\title{
The Role of Vitamin C in Amelioration of Hepatorenal Toxicity of Cefotaxime in Adult Albino Rats (Histological Study)
}

\author{
Maha Al Sammak ${ }^{1 *}$, Rana M. Ahmad ${ }^{1}$, Nadwa Alazzo² \\ ${ }^{1}$ Department of Anatomy, College of Medicine, University of Mosul, Mosul, Iraq; ${ }^{2}$ Department of Pathology, College of Medicine, \\ University of Mosul, Mosul, Iraq
}

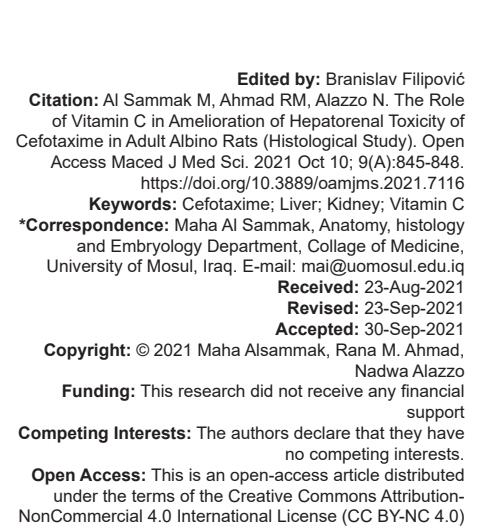

\begin{abstract}
AIM: Antibiotics have a great risk property, for this reason, the present work aimed to study the toxic effect of cefotaxime on histological examination of liver and kidney tissues as well as to detect the protecting role of Vitamin C.

METHODS: Thirty-two male adult albino rats were divided into four groups each with (eight animals) as following: Group (1): As control group and they injected with normal saline. Group (2): They were injected with $200 \mathrm{mg} / \mathrm{kg} \mathrm{B.W}$. of cefotaxime. Group (3): They were injected with Vitamin C in dose $100 \mathrm{mg} / \mathrm{kg} \mathrm{B.W.} 1 \mathrm{~h}$ before they inject with 200 $\mathrm{mg} / \mathrm{kg} \mathrm{B.W}$. of cefotaxime. Group (4): It was given Vitamin C in dose of $100 \mathrm{mg} / \mathrm{kg} \mathrm{B.W}$. Animals in all groups were injected intraperitoneally as single daily dose for 14 consecutive days.

RESULTS: Results of cefotaxime treated group revealed that a significant liver tissue changes as hepatocytic vacuolation, necrosis, cholestasis with sinusoidal congestion, and dilatation also induced a histopathological change in the kidney including tubular epithelial degeneration, cast formation in renal tubules, inflammatory cells infiltration in the interstitium, and few glomeruli showed eosinophilic material deposition at the wall of bowman capsule. Adding Vitamin $C$ to third group induces amelioration in the histological features of liver and kidney seen in Group (2) while group of Vitamin $\mathrm{C}$ only showed a histological picture similar to control group.
\end{abstract}

CONCLUSION: From this study, we can conclude that Vitamin C has important hepato-renal protective effect.

\section{Introduction}

The appearance of resistance to various antimicrobial drugs and its rapid development had made infectious diseases caused by bacteria and fungi a big health problem [1]. Inhibiting peptide glycan layer synthesis from the wall of the cell produced by B-lactam which is a synthetic antibiotic active against Gram negative and Gram positive [2]. Cefotaxime is a semisynthetic cephalosporin with a wide activity range including its efficiency against most clinically relevant diseases [3].

Dynamic studies of cefotaxime in normal individuals show that $40-60 \%$ of single intravenous dose is expelled unchanged in the urine [4]. Cefotaxime is one of the third generation cephalosporin antibiotics that treat many diseases which are caused by variety of species of bacteria [5].

Acute bacterial meningitis results in significant morbidity and mortality with many complications such as learning disabilities, hearing loss, and brain damage. Hence, rapid treatment with accurate antibiotic such as cefotaxime is indicated as soon as possible [6].
Antibiotic with a broad spectrum activity as cefotaxime is active against aerobic and anaerobic bacteria and it's most active against Gram-negative bacteria [7]. Hence, it is used in the treatment of many infections such as typhoid fever, endocarditis, pneumonia, gonorrhea meningitis, and brain abscess but many side effects due to the cefotaxime may occur such as anaphylaxis, eosinophilia in addition to the toxic effects on the liver, kidney, stomach, and lung [8]. The parenterally administered cephalosporin including cefotaxime in treat moderate to severe infections can results in cases of drug induced liver disease [9] and hepatotoxicity is the most common toxic effect due to the third cephalosporin mainly cefotaxime [10] as such hepatotoxicity has found to be induced by other antibiotics as levofloxacin [11].

Vitamin $C$ is a water soluble vitamin which acts as antioxidant that can be used to ameliorate the hepato-renal toxicity induced by different agents [12], [13].

Therefore, the present work is aimed to find out the hepato-renal toxic effect of cefotaxime and the possible protective role of Vitamin $\mathrm{C}$ against this toxicity in rats. 


\section{Materials and Methods}

In this study, thirty-two male adult albino rats were separated into four groups, each one with eight animals as followings:

\section{First group}

Is the control group was injected with normal saline single dose daily intraperitoneally (I.P.) for 14 days.

\section{Second group}

It was injected with $200 \mathrm{mg} / \mathrm{kg} \mathrm{B.W.} \mathrm{of}$ cefotaxime, cefotaxime powder dissolved in distilled water to be ready for injection I.P. as single dose daily for 14 days.

\section{Third group}

It was injected I.P. with Vitamin C ampoule in dose $100 \mathrm{mg} / \mathrm{kg} \mathrm{B.W.} 1 \mathrm{~h}$ before the cefotaxime injection, after $1 \mathrm{~h}$ the cefotaxime was injected I.P. in a dose $200 \mathrm{mg} / \mathrm{kg} \mathrm{B.W}$. both of them were given single dose daily for 14 days.

\section{Fourth group}

Was given Vitamin C I.P. in a dose of $100 \mathrm{mg} / \mathrm{kg}$ B.W. a single daily dose for 14 days.

After 14 days, the rats were euthanized by inhalation of an intensive dose of diethyl ether in a glass desiccator. This practice was performed in accordance with guidelines of animal euthanasia. After that, dissection of the animals was done and liver and kidney organs were taken from all groups and placed in containers containing $10 \%$ neutral buffered formalin to fix the organs. Histological sect ions were prepared and stained using hematoxylin and eosin stains.

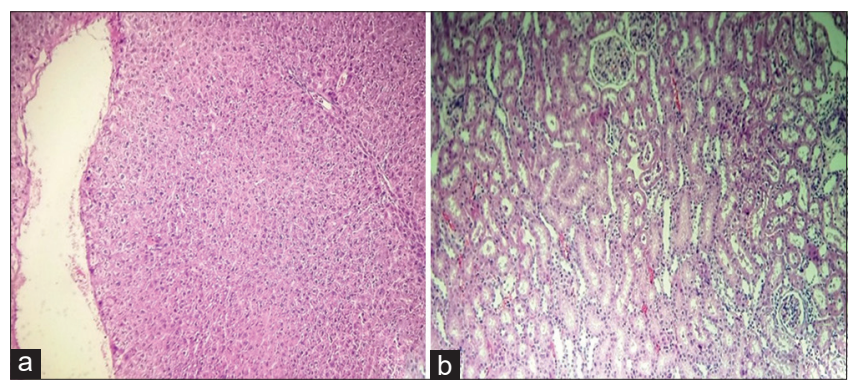

Figure 1: (a) Normal histological features ofliver (control) (Hand Ex100) (b) normal histological of kidney (control) ( $H$ and $E \times 100)$

\section{Histological Results}

\section{First (control) group}

Light microscopic study of both liver and kidney revealed no deviation in histological findings from those noticed in other normal tissues as shown in Figure 1.

\section{Second group}

The pathological changes that observed in the liver are congestion, sinusoidal dilatation, cholestasis, degenerative vacuolation, and some of hepatocytes showing necrosis with inflammatory cells infiltration (Figure 2).

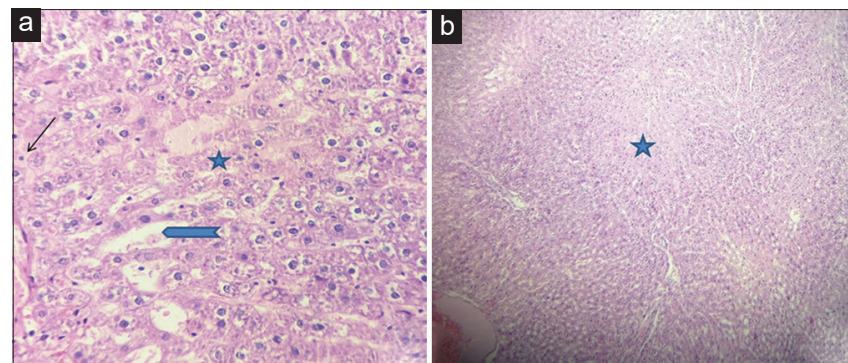

Figure 2: Liver of second group shows necrosis of hepatocytes (blue star), sinusoidal dilatation (blue arrow), inflammatory cells infiltration (thin black arrow) $(A$ : $H$ and $E \times 400),(B$ : $H$ and $E \times 100)$

While the changes in the kidney were includes flattening of renal tubules epithelium, proteinaceous material (cast) in the lumen of both proximal and distal tubules in addition to eosinophilic material around the glomeruli along the bowman capsule (Figure 3).



Figure 3: (a) Kidney of second group with cast formation at distal tubules (blue arrow), attenuation of lining epithelium (yellow arrow) ( $H$ and $E$ $\times 100$ ) (b) hyaline material deposition at bowman capsule (green triangle), degeneration of lining epithelium of proximal and distal tubules (black arrow), lymphocytic infiltration of interstitium (blue star) $(H$ and $E \times 400)$

\section{Third group}

Liver with sinusoidal dilatation and hepatocyte degeneration is less than second group with multiple small 


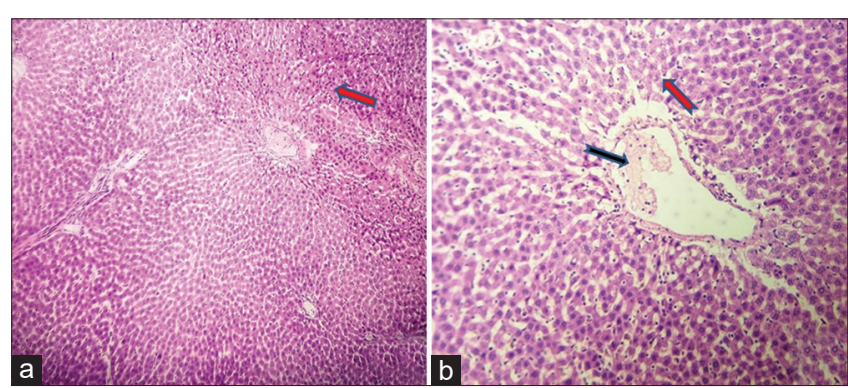

Figure 4: Liver of third group shows congestion, sinusoidal dilatation (black arrow), hepatocyte vacuolation and degeneration are less than second group (red arrow) $(A: H$ and $E \times 100)(B$ : $H$ and $E \times 400)$

foci of chronic inflammatory cells infiltration (Figure 4). The kidney shows cytoplasmic vacuolation of tubular epithelium in addition to inflammatory cells infiltration while the cast formation in the tubular lumen and the deposition in the bowman capsule is disappeared (Figure 5).

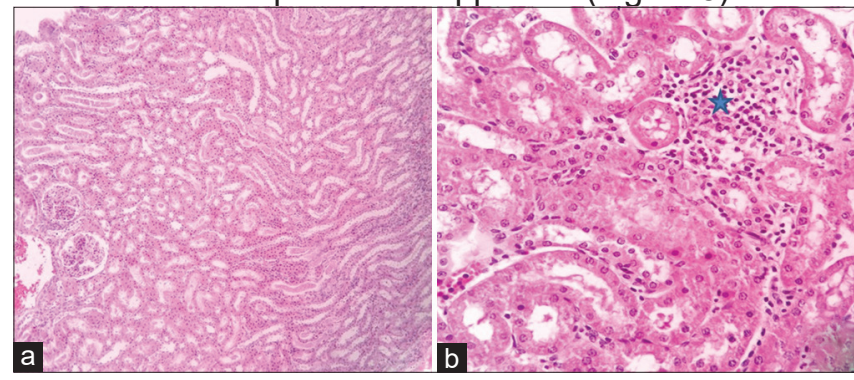

Figure 5: (a) Kidney of third group shows improved histopathological fractures of normal looking glomeruli and decrease tubular epithelium atrophy. (b) Kidney of third group shows inflammatory cells infiltration (blue stat) $(A: H$ and $E \times 100)(B: H$ and $E \times 400)$

\section{Fourth group}

The liver with preserved the normal histologica features without prominent changes apart from small foci of chronic inflammatory cells infiltration in between the hepatocytes, the same thing regarding the renal tissue with no prominent pathological changes of the tissue (Figure 6).

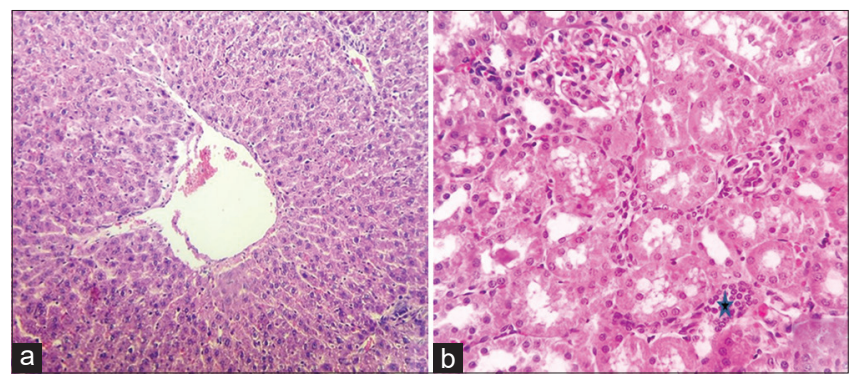

Figure 6: (a) Liver of fourth group with no significant histological changes ( $H$ and $E \times 100)$ (b) kidney of same group with normal looking glomeruli and tubules with few inflammatory cells infiltration (blue star) ( $H$ and $E \times 400)$

\section{Discussion}

Cefotaxime metabolism done in liver where it changes to active and inactive metabolites which later on excreted in high level by kidney in urine [14]
In the present study, rats of the second group show many changes in the liver tissue as hepatocyte vacuolation, necrosis, cholestasis with congestion, sinusoidal dilatation, and as seen in other studies that shown the similar effects on hepatic tissue [8], [15], [16], [17], with different degree of expression may be due to the amount of dose administration or the route of drug intake (IM, IV, or SC). The histopathological changes in the kidney of same group that treated with cefotaxime including tubular epithelial degeneration, cast formation in renal tubules, and inflammatory cells infiltration in the interstitium that corresponding the renal changes in other studies [8], [15], [16], [17], also in the present study, there were focal glomeruli show eosinophilic material deposition at the wall of bowman capsule surrounding the glomerular tufts that can be explained by the effect of cefotaxime as injurious substance to the capillary tuft with increasing the filtration ability of these glomeruli and deposition of these proteinaceous material [18].

The animals which received cefotaxime I.P. with Vitamin $\mathrm{C}$ in the third group the hepato-renal changes were seem ameliorated than the second group, the liver cells appeared with less cytoplasmic vacuolation, absence of necrosis, and decreased the congestion and sinusoidal dilation but the inflammatory cells infiltration is still identified in some focal areas while the renal tissue shows normal appearing glomeruli and the eosinophilic material deposition on the bowman capsule was disappeared, the renal tubular epithelium with less degenerative features apart from still inflammatory cells infiltration, these changes were declare the effect of Vitamin $\mathrm{C}$ as protective agent against the injurious effects of cefotaxime that shown in the second group, which was proved by other study that shown the hepato-renal protective effects of Vitamin C after using the ceftriaxone [19], [20] and others when used Vitamin $\mathrm{C}$ as protective agents against the effect of some drugs or toxic agents [12], [13], [21].

This means Vitamin $\mathrm{C}$ act as antioxidant agent against the oxidative stress and free radical produced by cefotaxime as done by Elkomy and his team who proved that olive oil as antioxidant can decreases biomarker oxidative stress (catalase and glutathione) in the tissues of liver and kidney of cefotaxime-intoxicated rats [7].

In this work, the fourth group when the rats were received Vitamin $\mathrm{C}$ only, there were no obvious histological changes in both hepatic and renal tissue in agreement with the results of other study [22]. It was clear that Vitamin C as the most effective antioxidant in avoiding lipid peroxidation and a potent free-radical scavenger [23], [24].

\section{Ethical Clearance}

The research was accepted by the medical ethical committee in University of Mosul, College of medicine. 


\section{Conclusion}

Vitamin $C$ has a good protecting effect against the hepato-renal toxicity of cefotaxime, therefore suggesting its uses as a potent hepatic and renal preventive agent.

\section{Acknowledgment}

I wish to express my great thanks to members of Veterinary College in Mosul University who assisted us during this study especially Dr. Al. Kassim-NAH, Assistant Prof. in physiology, biochemistry, and pharmacology department.

\section{References}

1. Al-Masoudi WA, Adam RS, Ghazi SS. Synthesis and antibacteria activity of new cefotaxime derivatives. Int $\mathrm{J}$ Pharm Res. 2021;13(1):156-9. https://doi.org/10.31838/ijpr/2021.13.01.026

2. Wadher SJ, PuraniK MP, Karande NA, Yeole PG. Synthesis and biological evaluation of Sciff base of Dapsone and their derivatives as antimicrobial agents. Int J PharmTech Res. 2009;1(1): 22-33.

3. Chin N, Neu HC. Cefotaxime and desacetyl cefotaxime: An example of advantageous antimicrobial metabolism. Diagn Microbial Infect Dis. 1984;2(3 Suppl):21S-31.

PMid:6086215

4. Matzke GR, Abraham PA, Halstenson CE, Keane WF. Cefotaxime and desacetyl cefotaxime kinetics in renal impairment. Clin Pharmacol Ther. 1985;38(1):31-6. https://doi.org/10.1038/ clpt.1985.130

PMid:4006373

5. Abood NK. New spectroscopic estimation of cefotaxime in pure and pharmaceutical formulation using environmental-friendly method. J Phys Conf Ser. 2021;1853(1):012023. https://doi. org/10.1088/1742-6596/1853/1/012023

6. Hathout RM, Sherihan G, Abdelhamid SG, El-Housseiny GS, Metwall AA. Comparing cefotaxime and ceftriaxone in combating meningitis through nose-to-brain delivery using bio/ chemoinformatics tools. Sci Rep. 2020;10(1):21250. https://doi. org/10.1038/s41598-020-78327-w

7. Elkomy A, El Sayed M, Elsayed F, Abd El Atey A. Amelorative effect of olive oil against hepatorenal toxicity of cefotaxime in albino rats. Int J Pharmacol Toxicol. 2020;11(12):96-106. https:// doi.org/10.14419/ijpt. v8i1.31179

8. Salman RJ, Hassoon ZA. Morphological and histological effect induced by cefotaxime, dexamethazon and mixture of them to the stomach, liver, kidney and lung of the rats. Drug Intervent Today. 2019;11(12):3311-9.

9. National Institute of Diabetes and Digestive and Kidney Diseases. Liver Tox: Clinical and Research Information on
Drug-Induced Liver Injury. Bethesda, MD: National Institute of Diabetes and Digestive and Kidney Diseases; 2012.

10. LarreyD.Druginducedliverdiseases.JHepatol.2000;32(1):77-88. https://doi.org/10.1016/s0168-8278(00)80417-1 PMid:10728796

11. Abdullah RA, Taee FD, Thanoon IA. Effect of levofloxacin on some body tissues in mice. Iraqi J Vet Sci. 2020;35(1):109-11. https://doi.org/10.33899/ijvs.2020.12646

12. Ahmad RM, Al-Hubaity AJ, Al azow NS. The role of Vitamin C on the structural changes of male albino rats kidney induced by tramadol. Ann Coll Med Mosul. 2019;41(1):57-62. https://doi. org/10.33899/mmed.2019.161285

13. Al-Jammas S. The Histological Changes Induced by Cisplatineum on the Kidney of Rats (with and without Vitamin C). [M.Sc Thesis]. Collage of Medicine, University of Mosul; 2011. p. 70-83.

14. Scholz H, Hofmann T, Noack R, Edwards DJ, Stoeckel K. Prospective comparison of ceftriaxone and cefotaxime for the short-term treatment of bacterial meningitis in children. Chemotherapy. 1998;44(2):142-7. https://doi. org/10.1159/000007106 PMid:9551246

15. Shaker SH, Razoogi QA, Shaban RK. Negative effect of therapeutic, double and overdose of cefixime on the liver and kidneys of male albino rats. Ann Trop Med Public Health. 2020;23(13B):SP231389. https://doi.org/10.36295/ASRO.2020.231389

16. Jazaa AA. Effect of Cefotaxime Administration on the kidney, liver and Lung of Swiss white Mice (Mus musculus). Tikrit J Pure Sci. 2017;22(6):1-7.

17. Soliman AM. Hepato-renal effects of cefotaxime in albino rats. Int J Pharm Pharm Sci. 2015;7(11):312-5. https://doi. org/10.1063/5.0027448

18. Tighe JR. The pathology of renal ischaemia. J Clin Pathol (Roy Coll Path). 1977;11(1):114-124. https://doi.org/10.1136/jcp.s3-11.1.114 PMid:269114

19. Adikwu E, Deo O. Hepatoprotective effect of Vitamin C (ascorbic acid. The protective role of Vitamin $\mathrm{C}$ against histological changes and some biochemical indices in liver of rats chronically exposed to Diazinon. Pharmacol Pharm. 2013;4(1):84-92. https://doi.org/10.4236/pp.2013.41012

20. Abu-Sheir WA. The protective role of Vitamin $C$ against histological changes and some biochemical indices in liver of rats chronically exposed to Diazinon. Egypt J Hosp Med. 2016;64(1):395-404

21. Ahmad RM, Al-Hubaity AJ, Al Azow NS. The role of Vitamin C against structural changes in testis of male albino rats induced by tramadol and its withdrawal. Coll Basic Educ Res J. 2021;17(2):1865-78. https://doi.org/10.33899/berj.2021.168581

22. Ibrahim HA, Mohammed HA, Shehata EB. Hepato-renal protective effect of Vitamin $C$ against toxicity induced by ceftriaxone in rats. Benha Vet Med J. 2019;36(1):107-18.

23. Abdel-Daim MM. Synergistic protective role of ceftriaxone and ascorbic acid against subacute diazinon-induced nephrotoxicity in rats. Cytotechnology. 2016;68(2):279-89. https://doi. org/10.1007/ s10616-014-9779-z PMid:25150555

24. Yussif NM, Abdul Aziz MA, Abdel Rahman AR. Evaluation of the anti-inflammatory effect of locally delivered Vitamin $C$ in the treatment of persistent gingival inflammation: Clinical and histopathological study. J Nutr Metab. 2016;2016: 2978741. https://doi.org/10.1155/2016/2978741

PMid:28050280 